\title{
Acute glycaemic management before, during and after exercise for cardiac rehabilitation participants with diabetes mellitus: a joint statement of the British and Canadian Associations of Cardiovascular Prevention and Rehabilitation, the International Council for Cardiovascular Prevention and Rehabilitation and the British Association of Sport and Exercise Sciences
}

\author{
John P Buckley (10) , ${ }^{1,2}$ Michael Riddell, ${ }^{3,4}$ Duane Mellor, ${ }^{5,6}$ Richard M Bracken, ${ }^{6}$ \\ Marie-Kristelle Ross, ${ }^{7}$ Andre LaGerche (D) , ${ }^{8,9}$ Paul Poirier $^{10}$
}

For numbered affiliations see end of article.

\section{Correspondence to} Professor John P Buckley, Shrewsbury Centre for Active Living, University of Chester Faculty of Medicine Dentistry and Life Sciences, Chester $\mathrm{CH} 1$ 4BJ, UK:

j.buckley@chester.ac.uk

Accepted 19 November 2020 Published Online First 23 December 2020
Check for updates

(C) Author(s) (or their employer(s)) 2021. No commercial re-use. See rights and permissions. Published by BMJ.

To cite: Buckley JP

Riddell M, Mellor D,

et al. Br J Sports Med

2021:55:709-720.

\section{ABSTRACT}

Type 1 (T1) and type 2 (T2) diabetes mellitus (DM) are significant precursors and comorbidities to cardiovascular disease and prevalence of both types is still rising globally. Currently, 25\% of participants (and rising) attending cardiac rehabilitation in Europe, North America and Australia have been reported to have DM (>90\% have T2DM). While there is some debate over whether improving glycaemic control in those with heart disease can independently improve future cardiovascular health-related outcomes, for the individual patient whose blood glucose is well controlled, it can aid the exercise programme in being more efficacious. Good glycaemic management not only helps to mitigate the risk of acute glycaemic events during exercising, it also aids in achieving the requisite physiological and psycho-social aims of the exercise component of cardiac rehabilitation (CR). These benefits are strongly associated with effective behaviour change, including increased enjoyment, adherence and self-efficacy. It is known that CR participants with DM have lower uptake and adherence rates compared with those without DM. This expert statement provides CR practitioners with nine recommendations aimed to aid in the participant's improved blood glucose control before, during and after exercise so as to prevent the risk of glycaemic events that could mitigate their beneficial participation.

\section{INTRODUCTION AND AIMS}

This guidance statement is aimed at helping frontline practitioners better manage the growing number of cardiac rehabilitation (CR) participants who have diabetes. ${ }^{1}$ It has been developed and written by a group of practitioner-academics with a special interest in how diabetes management interacts with their practices in cardiology (three authors), dietetics (one author), rehabilitation therapy (one author) or exercise science applied to metabolic care (two authors). All of the authors have previous experience in contributing to national and international practice guidelines/ standards in either CR and/or diabetes. They have been brought together to combine their expertise to represent the multi-professional CR associations of the UK and Canada, who are partnered with 38 other countries that make up the International Council of Cardiovascular Prevention and Rehabilitation (ICCPR). This means that the statement has also been reviewed and endorsed by doctors, nurses, physiotherapists, exercise physiologists, dietitians and psychologists representing health professionals and groups from around the world. The statement is laid out in two parts; Part 1 is a summary table (table 1 ) of nine key recommendations on managing glycaemic control in and around exercise, and Part 2 provides the evidence-based consensus that underpins these recommendations.

\section{PART 1}

The summary guidance statements in table 1 include scores (+sign in brackets) from the GRADE* system $^{2}$ for evidence quality, which was used in the development of the recent Diabetes UK Nutritional Guidelines. ${ }^{3} 4$

Part 2

\section{BACKGROUND}

Evidence search and review

The search and review strategy involved using health and medicine databases (CINAHL, PubMed, MEDLINE, Embase and TRIP). Initial searches commenced by reviewing existing key position statements and guidelines from other national and international associations that combined the topics of exercise, cardiovascular health/rehabilitation, diabetes and glycaemic management. The only statement which was most closely allied to this same focus was the 2012 position statement of the American Association of Cardiovascular and Pulmonary Rehabilitation (AACVPR). ${ }^{56}$ More recently (2019), the European Association of Preventive Cardiology 
Table 1 A summary of nine key statements for managing glycaemic control in cardiac rehabilitation participants before, during and after exercise

\begin{tabular}{ll}
\hline $\begin{array}{l}\text { Guidance } \\
\text { point }\end{array}$ & Recommendation \\
\hline 1 & More than $25 \%$ of cardiac rehabilitation ${ }^{8}$ participants will have diabetes mellitus (DM) and over $90 \%$ of these will be type 2 diabetes mellitus (T2DM). Participants \\
should be categorised into one of three levels of observation for exercise related to dysglycaemia risk, \\
a. Participants with type 1 diabetes mellitus (T1DM), have the greatest risk of exercise-related dysglycaemia (ie, hypoglycaemia or hyperglycaemia) and require \\
the greatest level of individualised management to maintain stable glycaemic levels (+++), \\
b. Participants with T2DM on insulin or insulin secretory medications are the next level of risk to warrant moderate to similar levels of observation for \\
dysglycaemia as those with T1DM (+++), and \\
c. Participants with T2DM on all other medications or managed with nutrition and lifestyle, usually require little additional observation compared with CR \\
participants without diabetes (NR). \\
Exercise should only to be contraindicated for CR participants with DM when one of the following states persists: \\
a. Recent history of 'brittle'/unstable glycaemic control (ie, four or more episodes of severe hypoglycaemia and hyperglycaemia with diabetic ketoacidosis, without \\
obvious or apparent causes and requiring emergency response and/or hospitalisation, over the last 12 months). These individuals are typically on exogenous \\
insulin and have a T1DM diagnosis (NR). \\
b. Low glucose level (<5 mmol/L) that is not reversed by nutritional supplementation in a short period of time (<30 min) (NR). \\
c. In participants with T1DM, where hyperglycaemia is $>15$ mmol/L and ketones $>1.5$ mmol/L (NR). \\
d. In T2DM, where there are ketones $>1.5$ mmol/L (++).
\end{tabular}

3 CR services should now possess glucose and ketone monitoring devices, and where the team includes practitioners skilled in taking these measures, in an equivalent standard to monitoring blood pressure, measuring ECG and providing cardiac life support (NR).

$4 \quad$ For CR participants with DM, the value of regular physical activity is of even greater value than for those participants without DM, as it has significant influences on these two key independent and interdependent morbidities $(+++) .{ }^{7}$ Unfortunately, uptake, adherence and completion of a CR programme has been found to be poorer in CR participants with DM versus those without DM (++). Participants with DM on insulin therapy are typically more fearful of glucose exertion related events (both during or for several hours after the exercise session has ended) and therefore need greater individualised attention, support and guidance to optimise management. CR programme managers therefore need to adopt strategies to overcome both the service and psychological motivation challenges of this large and increasing subgroup of CR participants (NR).

$5 \quad$ For those participants managing their DM with insulin, the following guidance is recommended:

a. Before exercise, prandial insulin, if administered just before the activity, should be injected into the abdomen or upper buttock. Ideally, the bolus (prandial) insulin dose should be reduced by $25 \%$ to $50 \%$ if an exercise session is within the time action period for that insulin (ie, within 2 hours of prandial insulin). Consider up to a $50 \%$ reduction to prandial insulin with next post-exercise meal and, if engaging in regular exercise, a $20 \%$ reduction to daily basal insulin dose (multiple daily injections only). For those on pump therapy, basal rates can be reduced by $50 \%$ to $80 \% 60$ to $90 \mathrm{~min}$ before the onset of exercise and rates can be resumed after the exercise is done (++).

b. Participants with less stable T1DM should be on continuous glucose monitoring and the CR team should support needs to pursue more vigilant care in working with the participant's diabetes care team (++).

6 Risk management related to chronicity, should respect that:

a. Increased age is associated with greater risk of hypoglycaemia (+++).

b. Over the longer term, unlike T2DM, exercise in T1DM does not typically improve glycaemic control substantively, but is associated with reduced risk for diabetes-related complications (+++).

7 In all cases and to promote the value of exercise, all should be done to reverse a contraindicated state before deciding to cease the exercise opportunity. Even if it means cutting the exercise session short while waiting for glycaemia and ketones to return to acceptable levels as detailed in sections 6 and 7 of the full report. Mild-to-moderate aerobic exercise can be started if blood ketones are low $(<0.6 \mathrm{mmol} / \mathrm{L})$ or the urine ketone dipstick is less than $2+$ (or $<4.0 \mathrm{mmol} / \mathrm{L}$ ) Blood glucose concentrations should be monitored during exercise to help detect whether glucose concentrations increase further. Strategies for preventing hyperglycaemia or hypoglycaemia include:

a. Lighter intensity aerobic activity (walking, light cycling, etc) for those starting in a hyperglycaemic state (++).

b. For participants with $T 1 \mathrm{DM}$, if glucose is $>10 \mathrm{mmol} / \mathrm{L}$, then it is recommended to perform the aerobic exercise component of the session first before the strength and/or more anaerobic type activities (+).

c. Performing resistance-type activities before aerobic type exercise is better suited to prevent hypoglycaemia, including those starting in an euglycaemic state.

d. For those in a lower glycaemic state $(<5.0 \mathrm{mmol} / \mathrm{L})$, nutritional supplements of simple carbohydrates of 15 to $30 \mathrm{~g}, 30$ min pre-exercise plus 25 to $30 \mathrm{~g}$ for every additional 30 min of activity (+).

e. Hypoglycaemia during exercise should be treated with 15 to $30 \mathrm{~g}$ of rapid acting carbohydrate (glucose tabs, juice, etc). Exercise can be resumed once glucose levels rise $>5.0 \mathrm{mmol} / \mathrm{L}$.

f. For T1DM and T2DM individuals on insulin, Section 6 provides the full details of recommendations for participants in one of five pre-exercise glycaemic categories: $<5 \mathrm{mmol} / \mathrm{L} ; 5$ to $6.9 \mathrm{mmol} / \mathrm{L} ; 7$ to $10 \mathrm{mmol} / \mathrm{L} ; 10.1$ to $15 \mathrm{mmol} / \mathrm{L}$; and $>15 \mathrm{mmol} / \mathrm{L}$ (NR).

8 There are a number of interactions between exercise and cardiovascular and non-insulin glycaemic management medications (see table 2, Part 2).

a. These medications do not cause a need for extra carbohydrates to be taken with exercise: Biguanides (eg, metformin) and incretin-based therapies of GLP1-RA, DPP-4 inhibitors (+).

b. These medications do require the monitoring of blood glucose and risk of hypoglycaemia and the need for taking of extra carbohydrate: Sulphonylureas and glinides (++).

c. A more recent medication for diabetes is the sodium-glucose cotransporter-2 (SGLT-2) inhibitor mainly prescribed for individuals with T2DM, and sometimes in T1DM under very specific circumstances. These glucose lowering agents are principally seen as an add-on therapy when metformin alone is not sufficient to reach the glycaemic target. The SGLT-2 inhibitors have shown benefits in patients with cardiovascular disease, however, ketoacidosis, has been reported in the absence of hyperglycaemia. Interactions with exercise are unknown, but recommendations already given for vigilance in monitoring of hypoglycaemic and hyperglycaemic prevention and management would seem prudent (see section 4.1, Part 2) (++).

d. For participants prescribed beta blocking agents, DM also attenuates the heart-rate response to exertion (and similarly for oxygen uptake responses) when either exercise commences or when exercise intensity is increased. It would seem prudent for CR participants with diabetes on beta-blockers to expect a further reduction in heart rate responsiveness to any given change in exercise intensity compared with beta-blocked CR participants without diabetes (NR).

9 c. The time of day (circadian effects) of exercise also influences glycaemic regulation in both T1DM and T2DM. In those who are at risk of post-exercise hypoglycaemic events, morning exercise is recommended and for those more prone to hyperglycaemia, afternoon and evening exercise (including high intensity interval training in T2DM) has been demonstrated as preferable (NR). 


\begin{tabular}{l} 
Table 1 Continued \\
\hline $\begin{array}{l}\text { Guidance } \\
\text { point } \quad \text { Recommendation }\end{array}$ \\
\hline${ }^{*}$ GRADE system scores of evidence quality \\
${ }_{++++}^{++}$strong recommendation based on high-quality evidence. \\
${ }^{+++}$moderate recommendation based on moderate-quality evidence. \\
${ }^{++}$low-strength recommendation based on low-quality evidence. \\
${ }^{+}$very-low strength recommendation based on very-low quality evidence. \\
CR, cardiac rehabilitation; NR, not rated.
\end{tabular}

$(\mathrm{EAPC})^{7}$ produced guidelines but these focussed on principles of exercise prescription and outcomes in type 2 diabetes mellitus (T2DM), as opposed to our focus on mitigating acute risks from exercise of glycaemic events in $\mathrm{CR}^{8}$ participants with either type 1 diabetes mellitus (T1DM) and T2DM. Following this, we searched and reviewed landmark review and consensus statements reporting on acute glycaemic management during exercise in people with diabetes from the past 10 years. ${ }^{9-21}$ In noting the dates of the cited evidence in these statements, our final search involved the reference lists of the cited evidence and then searching and reviewing individual studies beyond the last date where guidelines did not yet exist. Our review and consensus not only included the efforts of the authors but also a second level checking by the council members of the multiprofessional societies of the British and Canadian Associations of Cardiovascular Prevention and Rehabilitation, the British Association of Sport and Exercise Sciences and the ICCPR. In considering evidence quality, the authors wish to emphasise that this consensus statement focusses on pragmatic acute matters of safety and behavioural efficacy of completing individual exercise sessions. The systematically reviewed guidance on following appropriate risk stratification published by one of our authors on exercise safety in T1DM and T2DM 22 provides a key example of our underpinning rationale in translating applications into the arena of CR. Furthermore each of the Guidance notes in table 1 have been scored with the GRADE system for evidence quality ${ }^{2}$ as applied in recent Diabetes UK guidelines led by another one of our authors. ${ }^{3}$ If the guidance in this new statement can aid practitioners in reassuring CR participants with DM that they are safe to exercise and this positively influences their participation behaviour, then it has fulfilled its aims. As a result, it has been realised that much future research is required to evaluate the efficacy of these recommendations in terms of participant behaviour and education efficacy. As always, the largest challenge to outcomes in physical activity and exercise, whether in public health or rehabilitation/secondary prevention, is not simply biomedical or physiological, they are the complex behavioural interactions influenced by society, psychology, genetics and lifestyle impositions.

\section{Identifying the need}

T1DM and T2DM are significant precursors and comorbidities to cardiovascular disease and the prevalence of both types is still rising globally. ${ }^{23-25}$ Pan-European data show that over $25 \%$ of people with established coronary heart disease have a history of DM, where $>90 \%$ have T2DM. ${ }^{76-28}$ Compared with T2DM, T1DM has a greater overall cardiovascular disease risk. ${ }^{29}$ Risk factor analyses have also identified specific DM associations for heart failure, stroke and peripheral vascular disease. ${ }^{3031}$ Therefore, modern programmes of CR need to have their staff able to manage additional exercise considerations for DM. A recent Position Paper from the EAPC provides guidance on exercise prescription for people with T2DM participating in cardiovascular disease (CVD) prevention and rehabilitation programmes. ${ }^{7}$ The prevalence of T1DM is also increasing globally $^{3233}$ and a majority of this population also develop macrovascular disease at rates similar to what is observed in T2DM. ${ }^{34}$ Although the glycaemic control of individuals with T1DM ${ }^{35}$ and $\mathrm{T}_{2} \mathrm{DM}^{36}$ remains a major challenge in both developed and developing countries, considerable evidence supports the concept that regular physical activity and exercise programming benefits both T1DM and T2DM groups in the prevention of microvascular and macrovascular disease progression. ${ }^{1011} 13$

\section{RATIONALE, AIMS AND FRAMEWORK OF THIS STATEMENT}

Although the debate continues on whether improved glucose control in those with CVD actually helps to prevent further DM progression, ${ }^{37}$ it is clear that poor glycaemic management will mitigate the performance of optimally safe, effective and enjoyable physical activity for the CR participant. ${ }^{38}$ As noted earlier, key statements on the guidance and numerous health benefits that exercise confers in individuals with diabetes already exist from a number of international authorities from Canada, Europe and the USA. ${ }^{67910131539}$ This current Statement neither aims to review the physiological and long-term health benefits of increased physical activity in people with cardiovascular and metabolic disease nor to supersede these other published guidelines. This current consensus statement specifically aims to focus on guidance for managing the acute glycaemic needs before, during and after an exercise session in CR participants with diabetes. The objectives for meeting the aims of this statement include the following elements:

- Factors influencing physical activity behaviour influenced by concerns around blood glucose management,

- Preventing incidences and/or managing hypoglycaemic or hyperglycaemic events,

- Preventing accidents, injury or symptoms from neuropathies leading to sensorimotor deficiencies, and

- Considering interactions between exercise and medications for the CR participant with diabetes.

The above elements will be covered in three main sections:

1. Overarching considerations for all participants with DM (Sections 3 to 5);

2. Specific glycaemic risk and management in T1DM (Section 6);

3. Specific glycaemic risk and management in T2DM (Section 7).

Section 8, provides some brief notes regarding exercise intensity interactions with obesity and Section 9 the conclusion.

\section{OVERARCHING CONSIDERATIONS; BEHAVIOUR, SCREENING} AND ACTIVITY INTENSITY

\section{Behavioural considerations}

Globally, it is estimated that the behaviour of physical inactivity is a cardiovascular disease risk factor found in up to $\sim 45 \%$ of 
individuals, for whom many have cardiovascular disease, T2DM or cancer (breast and colon); in some western higher-income countries the prevalence of inactivity rises to $70 \% .{ }^{40}$ It is therefore likely that many people entering a CR programme, including participants with diabetes, will have a history of physical inactivity and naturally requiring a staged approach of targeted lifestyle behavioural-change strategies. It is a large enough challenge to get CR participants more physically active to any degree, let alone achieving the minimum targets recommended for an exercise-based rehabilitation programme (ie, $>60 \mathrm{~min}$ per week at an intensity $\geq 2.5$ metabolic equivalents). ${ }^{42-44}$ One of the key challenges to CR participation is the perceived health risk to participation. ${ }^{45} 46$ This fear is further compounded in those with DM, especially those with T1DM, where there is an added fear of hypoglycaemia and its consequences. ${ }^{13} 4748$ Even if CR participants with diabetes take up participation in $\mathrm{CR}$, their physical activity goal attainment is poorer compared with participants without diabetes. ${ }^{1749}$ Hypoglycaemia is also a barrier for engagement in exercise for those individuals with T2DM who are on insulin therapy or sulphonylureas. ${ }^{50}$ In some settings, high intensity exercise may promote a rise in glucose resulting in hyperglycaemia in patients with T1DM and some with T2DM, ${ }^{5152}$ and this may also be perceived as a barrier to participate. For example, if a CR participant arrives to join an exercise group whose blood glucose is at a relatively contraindicated level for exercise of too high or too low a level (ie, $>15 \mathrm{mmol} / \mathrm{L}$ or $<5.0 \mathrm{mmol} / \mathrm{L}$ ) and is turned away, he/she may leave with the wrong perception, which has been reinforced by the rehabilitation or healthcare practitioner; exercise is risky and something to be avoided (see specific guidance later for contraindication differences between T1DM and T2DM).

While many individuals with T2DM may not be provided with self-monitoring devices for blood glucose, it seems prudent for cardiac rehabilitation practitioners, in the pursuit of participant safety, education and achievement, to invest in capillary blood glucose and ketone level monitoring devices in a similar way to having the use of blood pressure monitors. ${ }^{43}$ Qualitative evidence has reported, on balance, that continuous monitoring in T1DM led to improved exercise management. ${ }^{53}$ Furthermore, patient education on how exercise can acutely and chronically influence changes to blood glucose management has been demonstrated to be efficacious. ${ }^{54-56}$ While specific evidence for CR participants with DM is needed in evaluating blood glucose monitoring, in T2DM such monitoring before and during the exercise session as part of tailoring the mode, intensity and type of exercise has been shown to minimise acute glycaemic disturbances and improve chronic glycaemic control in T2DM. ${ }^{57-59}$ As an example, if glucose levels tended to be on the higher end $(>8.0 \mathrm{mmol} / \mathrm{L})$, then milder intensity aerobic exercise could be initiated first, while if glucose levels were on the lower end (ie, $<5.0 \mathrm{mmol} / \mathrm{L}$ ), a carbohydrate snack could be provided and/or more intensive but brief aerobic activity or resistance training could be initiated first (see guidance and evidence in specific sections on risk management in Sections 6 and 7 on T1DM and T2DM, respectively). Overall, having glucose and ketone monitoring available can aid in more personalised exercise safety and efficacy.

Assessing and managing participants' risk, as per the next sections, must be performed in a manner that clearly highlights the benefits to metabolic and cardiovascular health of being more physically active. Following an appropriate behavioural evaluation of the CR participant, the practitioner needs to carefully determine whether a typical biopsychosocial approach can be taken or if there is a need for a more specialised psychobiological approach. ${ }^{60} 61$ The former approach focusses on the usual adapting behaviour to meet an 'ideal' prescription as outlined by the EAPC, ${ }^{7}$ whereas the latter approach requires adapting the exercise prescription to the current psychosocial state (including perceived barriers) of the participant. In this latter case, the participant needs to be supported to move towards agreed goals of optimised (but sometimes still not ideal) achievable behavioural and physiological targets. A place to start behaviour change could be in something as simple as considering ways to avoid sedentary behaviour; that is, avoiding time spent sitting or by breaking up prolonged periods of sitting with any non-exercise activity in a standing position or light activity. ${ }^{10} 62$ In T2DM, simply reducing sedentary time that encourages even increased amounts of daily light activity (starting with standing), improves glycaemic control. ${ }^{63}$ These benefits have been shown to be independent, but not as a substitute, of recommended levels of physical activity and are increasingly being shown to favourably influence cardiometabolic profile in people with diabetes. ${ }^{62}$ 64-66 A whole consensus statement on improving CR participant behaviour affected by other comorbidities, such as diabetes, beyond current recommendations ${ }^{43} 67$ is certainly warranted

\section{General considerations for monitoring, screening and managing acute risk \\ Record keeping and monitoring glyacaemic changes}

Given that there are many CR participants with DM, practitioners are recommended to create an specific section in their records on DM glucose and medication management. In order to determine acute blood glucose (and ketones if required) interactions before, during and after sessions (up to 24 hours for T1DM), levels should be recorded to identify trends that could either help improve glucose and related symptom management or demonstrate chronic improvements or declines in control. The specific factors requiring recording should are identified in each of the key sections to follow, including: contraindicatory events; sensory motor function; DM medication side effects exacerbated by exertion; DM and heart disease medication interactions occurring/exacerbated; times of day of glycaemic events occurring; management strategies (acute and chronic nutrition and medication factors) implemented.

\section{Screening and managing risk}

Most CR participants with diabetes are likely to be T2DM, by noting that $\sim 10 \%$ of all people with diabetes are T1DM (Diabetes UK; www.diabetes.org.uk). The main acute risks before, during or after exercise include: (1) hypoglycaemia, (2) hyperglycaemia with ketoacidosis, (3) adverse events related to neuromotor, visual or sensory insufficiencies and/or (4) fatigue relating to other comorbidities, for example, renal disease and dehydration. ${ }^{10} 1438 \mathrm{CR}$ participants with T1DM, as compared with T2DM participants, are at much greater risk of an exertionrelated glycaemic event from acute exercise (eg, hypoglycaemia, hyperglycaemia or ketoacidosis), along with having a greater challenge in achieving consistent 'optimal in-range' glucose levels. $^{13} 16$

Glycaemic stability and reducing the risk of undesirable exertion-related glycaemic events during an exercise session are recommended to be best achieved through performing a mixture of aerobic, strength and interval-type training activities. ${ }^{10}$ Overall, the glycaemic responses to exercise in general is highly variable in T1DM, although some reproducibility does exist within patients. ${ }^{5168}$ To help limit hypoglycaemia risk, 
performing resistance-type activities before aerobic type exercise is better suited for those patients with T1DM who are relatively euglycaemic before exercise onset. ${ }^{69}$ In contrast, if individuals with T1DM (or T2DM) have mild hyperglycaemia (defined here as a glucose between 9.0 to $15.0 \mathrm{mmol} / \mathrm{L}$ ), then initiating a session with some aerobic exercise (eg, walking, jogging, cycling) will tend to reduce blood glucose levels toward a euglycaemic level. ${ }^{13}$ Recent evidence in T1DM participants suggests that blood glucose levels increase significantly with high intensity exercise as compared with moderate continuous intensity exercise. ${ }^{70}$ Post exercise hypoglycaemia is also common in T1DM, ${ }^{13}$ and may result in nocturnal hypoglycaemic seizures, particularly if post exercise insulin dose reductions have not been managed properly. ${ }^{71}$ Specialist diabetes clinicians, who are already working with the CR participant, should be informed from the CR team of any events that occur in and around physical activity or exercise sessions. This will ensure that patient records are updated and adapted to the best possible individualised care plan.

\section{Putting contraindications into context for light-to-moderate and vigorous physical activity}

The key priority of all CR professionals is to provide advice and education to patients on the actions that should be taken if and when a participant is relatively contraindicated to performing physical activity. The guidance notes to follow must not be confused with standard contraindications for 'maximal exercise testing' typically outlined by the British Association of Sport and Exercise Sciences and the American College of Sports Medicine $(\mathrm{ACSM})^{1739}$ where glycaemic dynamics to specific incremental maximal exercise test protocols are distinctly different to the types of exercise which occur in most CR settings. Though, some may challenge this thinking, with the increasing number of studies involving repeated maximal bouts of highintensity interval training (HITT). A key difference, however, between a maximal exercise test and HIIT training, is the former normally applies a relentless incremental staged or ramped protocol towards maximum, where the latter involves regular intervals of active recovery at low-to-moderate intensity. More research is thus required on comparing the glycaemic dynamics involved in these two forms of maximally achieved exertion.

The level of contraindication decision-making criteria and actions, in order of priority, should be as follows:

- Participants should not perform exercise if presenting with any significant signs and symptoms of a potential acute diabetes event, such as a recent episode of severe hypoglycaemia or ketoacidosis (blood ketone levels $>1.5 \mathrm{mmol} / \mathrm{L}$ before exercise onset in individuals with T1DM) which requires urgent medical attention/intervention. ${ }^{13}$ Though not common in T2DM, ketoacidosis can occur, and the same urgent attention should be given for blood ketones levels $>1.5 \mathrm{mmol} / \mathrm{L}^{72}$

- Participants should not perform exercise if they have described a recent history of unstable (sometimes called 'brittle') diabetes where they experience wide unpredictable swings between hyperglycaemia and hypoglycaemia, especially where this is often linked with psychosocial difficulties; it needs the input of an expert multidisciplinary team. ${ }^{73}$ In this case, any form and intensity of physical activity could potentially exacerbate the risk of an acute adverse glycaemic event. The specific target levels for hypoglycaemia and hyperglycaemia and related management are outlined in each of the Sections 6 and 7 for T1DM and T2DM, respectively.
- Before excluding a participant from exercise, all should be done to rectify signs and symptoms of potential relative or absolute hypoglycaemic or hyperglycaemic contraindications and to get the patient to be active, even if only at light intensities. Specific details on this issue are described in Sections 6 and 7.

\section{Sensorimotor considerations}

Sensory and motor disturbances in diabetes are common and may increase the risk for falls and injury. ${ }^{74}$ Care should be taken to maximise safety and minimise foot injuries associated with increased levels of physical activity in these patients, including balance assessment and regular foot exams. ${ }^{75}$ While not directly related to acute glycaemic management, many complications of diabetes can compound the problems associated with hypoglycaemia or hyperglycaemia, which thus limit the ability of participants performing physical activity. These include: renal disease, where raised urea level is known to lead to fatigue $;^{76}$ retinopathy with concerns over activities that increase intraocular pressure; peripheral neuropathy linked with hand/foot ulcers and loss of motor sensation; autonomic neuropathy that affects recognising symptoms of angina and hypoglycaemia; reducing the ability of the heart rate to increase and reduced thermoregulation. ${ }^{14}$ If a CR participant with diabetes has known complications or appears to have symptoms suggesting loss of neuro or motor function, it is vital that immediate advice from specialists is sought. It is important to note however, that patients with advanced disease can still exercise if certain precautions are made including the supervision of exercise sessions by a qualified exercise specialist and a modified training programme.

\section{DIABETES INTERACTIONS WITH CARDIOVASCULAR MEDICATIONS}

\section{Beta blockers, heart rate and oxygen-uptake kinetics}

Beta-blocker medication, commonly taken by most CR participants, attenuates heart rate response and oxygen uptake kinetics during exercise. ${ }^{79}$ Diabetes also reduces the responsiveness of the heart rate to increased work demands (and similarly for oxygen uptake responses) when either exercise commences or when exercise intensity is increased. ${ }^{80}$ The potential mechanisms for this have been reported to be, but not yet fully agreed, either neuro-chronotropic ${ }^{80}$ and/or a result of lower activity/fitness levels linked with lowered left ventricular function. ${ }^{81} 82$ Until the evidence is clearer on the combined effect of diabetes and beta-blockade, it would seem prudent for CR participants with diabetes on beta-blockers to expect a further reduction in heart rate responsiveness to any given change in exercise intensity compared with beta-blocked CR participants without diabetes.

In individuals who manage their glycaemia with insulin administration (basal and/or bolus insulin) as well as considering any adjustments to doses with their diabetes specialist team; the site of injection should also be considered. ${ }^{13}$ It is thought that the increased blood flow associated with exercise in the legs or arms may increase the rate of uptake of insulin as compared with other insulin administration locations (abdomen, upper buttock). This could increase the risk of hypoglycaemia with exercise. It is generally advised that insulin administration should be limited to the abdomen or upper buttock if an exercise session is to be initiated post-insulin administration. ${ }^{83}$ However, this may not fully protect against exercise-associated hypoglycaemia and other preventative actions may be required (ie, insulin dose reduction, carbohydrate snacking). 52 84-87 


\begin{tabular}{|c|c|c|}
\hline Medicine & Effect on glucose & Extra $\mathrm{CHO}$ with exercise \\
\hline $\begin{array}{l}\text { Biguanides } \\
\text { (eg, metformin) }\end{array}$ & $\begin{array}{l}\text { In people with T2DM, metformin can reduce the decline in blood } \\
\text { glucose during acute aerobic exercise but the glycaemic effects of } \\
\text { metformin while performing exercise in people at risk of or with T2DM } \\
\text { appear transient and minor }\end{array}$ & No \\
\hline $\begin{array}{l}\text { Sulphonylureas (eg, glibenclamide or glimepiride) } \\
\text { / glinides (eg, nateglinide) }\end{array}$ & $\begin{array}{l}\text { Sulphonylureas should be taken with caution during acute exercise as } \\
\text { the combined influence of both can rapidly decrease blood glucose } \\
\text { levels and lead to hypoglycaemia. } \\
\text { There is little evidence to detail the impact of glinides on physical } \\
\text { exercise and metabolic outcomes. }\end{array}$ & $\begin{array}{l}\text { Check glucose with exercise and take extra } \mathrm{CHO} \\
\text { during exercise }\end{array}$ \\
\hline Thiazolidinediones (eg, pioglitazone) & No noted effect on blood glucose with acute exercise & No \\
\hline $\begin{array}{l}\text { Sodium glucose like transporter inhibitors (eg, } \\
\text { empagliflozin or canagliflozin) }\end{array}$ & Largely unknown, studies needed & Unknown \\
\hline $\begin{array}{l}\text { Incretin-based therapies } \\
\text { GLP1-RA: liraglutide } \\
\text { DPP-4 inhibitors: sitagliptin or saxagliptin }\end{array}$ & $\begin{array}{l}\text { GLP1-RA: No noted effects on blood glucose with acute exercise } \\
\text { DPP-4 inhibitors: unknown }\end{array}$ & No \\
\hline Insulin (eg, Tresiba or aspart) & $\begin{array}{l}\text { Promote hypoglycaemia with exercise; may need to reduce dose } \\
\text { before planned exercise }\end{array}$ & $\begin{array}{l}\text { Check glucose before, during and after exercise and } \\
\text { take extra } \mathrm{CHO} \text { if needed during exercise }\end{array}$ \\
\hline
\end{tabular}

CHO, carbohydrate; T2DM, type 2 diabetes mellitus.

Statins, traditional thiazides and some beta blockers can reduce glycaemic control in diabetes ${ }^{88-92}$ and in some patients metformin can reduce the benefits of atorvastatin. ${ }^{93}$ In relation to the interactions between medications, exercise and diabetes, there is much literature on beta-blockers either affecting liver glucose output, insulin release, muscle glucose uptake and reductions in hypoglycaemic symptom sensations (eg, tachycardia blunted). ${ }^{92} 9495$ Non-vasodilating beta-blockers (metoprolol, bisoprolol, atenolol and bucindolol) can negatively impact on glucose control but vasodilating beta-blockers (carvedilol and nebivolol) are reported to have little deleterious effect on glucose control. ${ }^{96}$ It is therefore important to check which betablocker the CR participant is taking, and to enquire with the medical team of the potential benefits of using a vasodilating beta-blocker.

It has also been reported that there are two negative effects of the blood glucose lowering medications from the sulphonylurea glibenclamide on normal exercise responses, which are important to $\mathrm{CR}$ participants:

I. The benefit of 'the warm-up' to prevent subsequent ischaemia during moderate to higher intensity exercise is impaired in those with stable angina, ${ }^{97} 98$ thus increasing the chances of exertion-related angina during a typical exercise session, and

II. The normal effect that exercise has on acutely reducing blood insulin during higher intensity exercise is significantly impaired, ${ }^{99}$ which means that higher intensity exercise could contribute to hypoglycaemia in those treated with gliclazide and other sulphonylureas.

Table 2 provides a summary of the interactions between common medications used in diabetes management and exercise.

\section{Euglycaemic ketoacidosis with SGLT-2 Inhibitors}

Sodium-glucose cotransporter-2 (SGLT-2) inhibitors are mainly prescribed in T2DM, but can also be used in T1DM under very specific circumstances. ${ }^{100-102}$ They are principally seen as an add-on therapy when biguanides (eg, metformin) alone are not sufficient to reach the glycaemic targets. The SGLT-2 inhibitors have shown benefits in patients with cardiovascular disease, ${ }^{103}$ making it an interesting choice in that population. However, ketoacidosis, even in the absence of hyperglycaemia, has been reported in patients taking SGLT-2 inhibitors. ${ }^{5}$ Although rare, this euglycaemic ketoacidosis is serious and could potentially be fatal if not recognised. ${ }^{100} 102$ In light of this evidence, any patients on SGLT-2 inhibitors should be asked to report if and when they have experienced symptoms of nausea, vomiting or malaise, and also other typical symptoms of ketoacidosis (increased urination frequency, thirst, abdominal pain, confusion, 'pear-drop breath', flushed face, fatigue, rapid breathing, dry mouth and skin). A concomitant decline in exercise performance would be a key sign of any of these symptoms of ketoacidosis and exercise would sensibly be contraindicated for a number of reasons in these instances anyway. The effects of SGLT2 antagonism on hypoglycaemia risk associated with exercise are unknown, but these medications typically result in lower glucose concentrations in general and more vigilant glucose and ketone monitoring (using portable ketone metres) around exercise seems prudent.

\section{TIME OF DAY OF EXERCISE INFLUENCES}

In addition to the effects of the timing of eating around exercise on glycaemic control, the time of day (circadian effects) of exercise also influence glycaemic regulation in both T1DM and T2DM. ${ }^{20}{ }^{104-106}$ In those patients to whom it is of concern to reduce the risk of post-exercise hypoglycaemic events, morning exercise is recommended and for those more prone to hyperglycaemia, afternoon and evening exercise (including HIIT in T2DM) have been demonstrated as preferable. ${ }^{104}{ }^{106-109}$ In these noted studies of morning exercise before breakfast $(\sim 0700$ hours), the post-breakfast glucose levels were actually more normal compared with having breakfast before exercise, with fewer hypos' in the subsequent 15 to 24 hours. However, fasted morning HIIT may promote a significant rise in glucose concentration in both T1DM and T2DM. ${ }^{106110}$ It is also important to note that post-exercise hypoglycaemic events can be delayed up to 15 hours, ${ }^{71} 111$ so it is important to inform CR participants to monitor their blood glucose levels more carefully in this period.

\section{SPECIFIC CONSIDERATIONS FOR TYPE 1 DIABETES}

A general rule is that those with T1DM are at higher risk of an exertion-related glycaemic event compared with those with T2DM. ${ }^{12}$ Managing blood glucose levels in and around exercise in people with T1DM is therefore more challenging and crucial than in T2DM. The guidance on glucose management 
summarised in table 1 is of most pertinence to this group of $\mathrm{CR}$ participants. While more evidence is required on efficacy, it would seem prudent for CR practitioners to now be skilled in using and include glucose and ketone monitoring devices as part of their standard equipment, in a similar way to having blood pressure, heart rate and ECG monitors.

Aerobic endurance type exercises (walking, jogging, light-tomoderate cycling) are likely to contribute to hypoglycaemia, whereas activities involving short bursts of higher intensity activity (sprints, weight training and circuit training) can contribute to hyperglycaemia. ${ }^{13}$ Unlike T2DM, where glycaemic control can be improved over time with increased levels of physical activity, in T1DM such improvements do not usually ensue. ${ }^{11112}$ Risk of severe hypoglycaemia increases markedly with age and disease duration in this population. ${ }^{113}$ In light of such a benefit paradox for T1DM, it is important to reinforce with CR participants that their main gain from the exercise is significant improvements in cardiovascular health and fitness. ${ }^{114} 115$ Specific to diabetes, the CR participant can be informed that increasing levels of physical activity and improved fitness can help in reducing the risk of retinopathy and moderately increased albuminuria. ${ }^{1316}$ For those people with T1DM and poorer glycaemic control, there is an increased chance of an atypically accelerated heart rate response at higher exercise intensities ( $>75 \%$ maximal heart rate) and it is important to observe the intensity of exercise at this point to determine if the participant is over-exerting themself. ${ }^{117}$ Poor glucose control is also associated with a greater risk for diabetic ketoacidosis in T1DM. ${ }^{113}$

While the recent advances in glucose management with continuous subcutaneous insulin infusion (pump) or closed-loop insulin pumps have reduced some of the burden of diabetes selfcare, through allowing freer independent care and freer living, the individualised nature of T1DM remains a challenge. ${ }^{118} 119$ This is especially true when setting individual insulin delivery levels in and around exercise, sports participation and nutrition. A tripartite team approach between the individual patient, the diabetes specialist (physician and/or nurse) and the exercise practitioner thus continues to remain an important factor in achieving quality, safe and effective care for the individual participant. Insulin treatment is essential as part of the management of T1DM, therefore when planning physical activity, the type and amount of insulin (affected by time of last injection and dose) as well as the time of the last carbohydrate containing meal (including quality and quantity) needs to be considered. The overarching considerations are whether the exercise is planned or unplanned, and the intensity and duration of the exercise. ${ }^{13}$ In general, lowering insulin pump basal rates needs to be made in advance of aerobic exercise by approximately 60 to $90 \mathrm{~min}$, if possible, to be effective in limiting hypoglycaemia. ${ }^{86}$ Insulin pumps can be beneficial for improving glucose control after exercise as compared with multiple daily injections, ${ }^{120}$ because they likely allow for temporary basal rate reductions to prevent post-exercise hypoglycaemia and bolus or basal rate corrections for post-exercise hyperglycaemia. ${ }^{13}$

\section{Contraindications for T1DM hypoglycaemia and hyperglycaemia levels and related management}

A comprehensive consensus statement by a group of international sport and exercise and diabetes experts ${ }^{13}$ provides initial guidance on encouraging the participation in physical activity. The guidance takes a proactive approach to mitigating, where possible, potential contraindications with the aim 'to do all that is possible' to increase physical activity and exercise participation in patients with T1DM. They state that the target blood glucose zone during exercise should be between 7 to $10 \mathrm{mmol} / \mathrm{L}$ (126 to $180 \mathrm{mg} / \mathrm{dL}$ ) and to quote the guidance directly from this consensus statement, ${ }^{13}$ the following systematic steps should be employed:

Blood glucose concentrations before exercise commencement and recommended glucose management strategies

The carbohydrate intakes shown here aim to stabilise glycaemia at the start of exercise. Blood glucose at the start of exercise must also be viewed within a wider context. Factors to consider include directional trends in glucose and insulin concentrations, patient safety and individual patient preferences based on experience. Carbohydrate intake will need to be higher if circulating insulin concentrations are high at the onset of exercise.

Starting glycaemia below target $(<5 \mathrm{mmol} / \mathrm{L} ;<90 \mathrm{mg} / \mathrm{dL})$

- Ingest 15 to $30 \mathrm{~g}$ of glucose before starting exercise.

- Delay exercise until blood glucose is $\geq 5 \mathrm{mmol} / \mathrm{L}$ ( $\geq 90 \mathrm{mg} /$ $\mathrm{dL}$ ) and monitor closely for hypoglycaemia.

Starting glycaemia near target $(5.0$ to $6.9 \mathrm{mmol} / \mathrm{L} ; 90$ to 124 $\mathrm{mg} / \mathrm{dL}$ )

- Ingest $10 \mathrm{~g}$ of glucose before starting aerobic exercise.

- Anaerobic exercise and high intensity interval training sessions can be started.

Starting glycaemia at target levels ( 7 to $10 \mathrm{mmol} / \mathrm{L} ; 126$ to $180 \mathrm{mg} / \mathrm{dL}$ )

- Aerobic exercise can be started.

- Anaerobic exercise and high intensity interval training sessions can be started, but glucose concentrations could rise.

Starting glycaemia slightly above target $(10.1$ to $15.0 \mathrm{mmol} / \mathrm{L}$; 182 to $270 \mathrm{mg} / \mathrm{dL}$ )

- Aerobic exercise can be started.

- Anaerobic exercise can be started, but glucose concentrations could rise.

Starting glycaemia above target ( $>15 \mathrm{mmol} / \mathrm{L} ;>270 \mathrm{mg} / \mathrm{dL}$ )

- If the hyperglycaemia is unexplained (not associated with a recent meal), check blood ketones levels. If blood ketones levels are modestly elevated (up to $1.4 \mathrm{mmol} / \mathrm{L}$ ), exercise should be restricted to a light intensity for only a brief duration $(<30 \mathrm{~min})$ and a small corrective insulin dose might be needed before starting exercise. If blood ketones levels are elevated $(\geq 1.5 \mathrm{mmol} / \mathrm{L})$, exercise is contraindicated and glucose management should be initiated rapidly as per the advice of the healthcare professional team.

- Mild-to-moderate aerobic exercise can be started if blood ketones are low $(<0.6 \mathrm{mmol} / \mathrm{L})$ or the urine ketone dipstick is less than $2+$ (or $<4.0 \mathrm{mmol} / \mathrm{L}$ ). Blood glucose levels should be monitored during exercise to help detect whether glucose levels increase further. Intense exercise should be initiated only with caution as it could promote further hyperglycaemia.

As part of symptom management in and around exercise, it is important to highlight and ensure that the patients learn the sensations of how they feel during exercise when their blood glucose levels are in the requisite safest exercise target zone (7 to $10 \mathrm{mmol} / \mathrm{L}$ ), including: heart rate, rating of perceived exertion (muscles and breathing), muscle fatigue and levels of perspiration. If patients lack this perception, then increased glucose monitoring is warranted. Especially for participants unaccustomed to exercise, individuals need to be able to differentiate between these normally raised responses during 'glycaemic safe 
exercise' compared with those same but often more noticeable responses which ensue from a state of hypoglycaemia.

Exercise that is longer in duration $(>60 \mathrm{~min}$ ) or at intensities likely to significantly lower muscle and liver glycogen stores (including interval or intense resistance training) can increase risk of late onset (ie, nocturnal) hypoglycaemia. In such cases, consumption of 10 to $30 \mathrm{~g}$ of carbohydrate during and within 30 min after completing this type of exercise is recommended. ${ }^{13} 14$ An alternative strategy could be to reduce the prandial insulin dose with a pre-exercise meal and at the next meal by $\sim 50 \%$ and/or reduce the basal (background) insulin by $\sim 20 \%$ in those on multiple daily injections (MDI), especially if performing exercise on multiple days. ${ }^{121} 122$ Basal dose reductions can also be made if the participant is performing multiple acute physical exercise sessions over successive days. ${ }^{84}$ Such strategies are important for a supportive environment for weight maintenance or loss while reducing risk of hypoglycaemia. Those on pump therapy should be advised to lower basal insulin rates overnight by $20 \%$, starting at bedtime for 6 hours, after an intensive exercise session that occurs in the afternoon or evening to help limit post-exercise nocturnal hypoglycaemia. ${ }^{13}$ This should be done in conjunction with the diabetes specialist team as individuals may vary in the effect of exercise on tissue insulin sensitivity. However, such strategies may be important for a supportive environment for weight maintenance or loss while reducing risk of hypoglycaemia.

\section{SPECIFIC CONSIDERATIONS FOR TYPE 2 DIABETES}

As noted, most CR participants with diabetes will be T2DM. For the large majority of T2DM participants, they will either be managed conservatively through diet or on medications such as metformin or sulphonylureas (table 1.). Sulphonylureas increase activity-related hypoglycaemia risk. ${ }^{123}$ As noted in Section 5, for those with T2DM undertaking morning exercise before 0900 hours in a fasted state, appears to reduce the risk of postexercise hypoglycaemia. ${ }^{105}$

For people with T2DM on insulin and in some cases on a continuous subcutaneous insulin infusion device (ie, insulin pump), the guidance for T1DM participants should suffice. For those on MDI, some evidence suggests a reduced risk of hypoglycaemia with insulin degludec versus insulin glargine in patients with T2DM, ${ }^{124}$ although in a randomised controlled trial with T1DM participants, there was an equivalent incidence of hypoglycaemia from acute exercise. ${ }^{125}$ It is noted that in T1DM, insulin degludec is somewhat more difficult to titrate down for a planned exercise event, as compared with other basal insulins, because of its very long half-life. ${ }^{122}$ If from this evidence in T1DM is applicable to T2DM, a basal rate reduction of insulin degludec by $20 \%$ may be warranted if patients are generally becoming much more physically active with CR.

Another somewhat paradoxical area of nutritional management has been the effects of sugar-free foods sweetened with aspartame conspiring with exercise to cause hypoglycaemia in T2DM. ${ }^{126}$ Traditional physiology is challenged here in explaining this phenomenon but the 'metabolic-conditioning survival instinct' from sensory psychobiological anticipatory responses to taste, smell or sight of 'sweet food' is the hypothesised explanation of these rises in endogenous insulin secretion. ${ }^{126}$

\section{Contraindications for type 2 participants, with hyperglycaemia and related management}

For participants with T2DM, in a hyperglycaemic state where blood glucose is $>17 \mathrm{mmol} / \mathrm{L}$, without ketosis and without symptoms, is not a contraindication to exercise but the exercise practitioner should have the patient proceed with some caution. ${ }^{107}$ Milder forms of exercise intensity are likely to promote a beneficial reduction in glycaemia. In respecting these American College of Sports Medicine ${ }^{127}$ recommendations, and more recent recommendations on the value of performing light activity to reduce blood glucose levels, ${ }^{10}$ the following approach is recommended:

- If the participant has no symptoms and feels well, they can perform 10 to $15 \mathrm{~min}$ of low intensity light activity, such as walking $\left(<40 \% \mathrm{VO}_{2}\right.$ max or heart rate reserve, Borg RPE $<11$ or Borg CR-10 <2.0), then blood glucose levels should be rechecked with the following guidance:

i. If blood glucose level has risen, then the participant needs to see a specialist to review, as this is not the expected response.

ii. If blood glucose level has fallen to 13 to $15 \mathrm{mmol} / \mathrm{L}$ then the light intensity activity should continue, and review at next session to see if a more favourable response has occurred; if not then review with diabetes specialist is recommended.

iii. If blood glucose level has fallen $<12 \mathrm{mmol} / \mathrm{L}$ then gradually progress towards completion of the normal exercise programme for that day and recheck at the end of the exercise session to see it has not risen again. As hyperglycaemia increases urine output, encouraging extra fluid intake may be prudent. They should be reviewed as soon as possible with the diabetes specialist to prevent this from becoming a common occurrence. If it is a new occurrence of such hyperglycaemia, a cautious approach may be to check blood glucose levels during subsequent exercise sessions.

iv. In all the above cases, the CR team must note this in the participant records, inform the participant's diabetes specialist clinician and review and check on the next visit.

- In keeping with recommendations for effective participant education and the development of self-management skills, ${ }^{42} 128129$ the CR team and the diabetes specialists should aim for the participant to learn, understand and be able to employ the above decisions and actions independently. This will ensure that the participant can become independently physically active safely and effectively.

\section{Management of type 2 participants with hypoglycaemia}

Overall, for asymptomatic T2DM participants being managed conservatively and not on medication or insulin, they should proceed similar to people without diabetes. In T2DM, preventable hypoglycaemia is the most common risk from physical activity, which is usually a function of inadequate nutrition and/ or timing of taking medication, especially insulin and sulphonylureas. ${ }^{142138130}$ Pre-exercise low blood glucose levels is only a contraindication if it cannot be raised to $>5.5 \mathrm{mmol} / \mathrm{L}$ through an acute nutritional intervention (ie, treated with 15 to $30 \mathrm{~g}$ of fast-acting carbohydrate such as dextrose). Please note earlier statements about counterintuitive effects of sugar-free foods sweetened with substitutes such as aspartame.

Key guidelines and reviews highlight that hypoglycaemia will occur either as a result of commencing activity with too low a blood glucose level prior to exercise or as a result of prolonged exercise (>30 min), which may be manifested during or post activity and can be delayed up to 15 to 24 hours. ${ }^{10} \mathrm{~A}$ key education point that should be noted for the CR participant is that regular aerobic exercise training will reduce the risk of endurance related hypoglycaemia as a result of enhanced fatty acid oxidative energy metabolism. ${ }^{14}$ In light of the ACSM 
recommendations ${ }^{10}{ }^{14}$ hypoglycaemia, in some ways is akin to hyperglycaemia where all individuals treated with insulin and insulin secretagogues (both sulphonylureas and meglitinides) are at risk of hypoglycaemia and therefore at an increased risk of exercise-induced hypoglycaemia. For patients on metformin alone, it is unlikely to cause hypoglycaemia, whereas those taking sulphonylureas either on their own or in combination with metformin increases the risk of hypoglycaemia exacerbated by exercise. Please also note the previous cautionary notes on the effects of diabetes impairing the 'warm-up effect' combined with reducing blood-insulin clearance caused by the sulphonylureas group of medications.

The risk of hypoglycaemia and how it is managed, in part, depends on whether the activity is planned or unplanned. In the formal CR setting, it is considered that all physical activity is planned. Additionally, when planning to manage hypoglycaemia risk, the duration and intensity of physical activity need to be considered. In individuals managed with treatments (insulin and/ or insulin-stimulated agents) that increase the risk of hypoglycaemia the following precautions should be taken:

- Consider the duration of action of the medications, some insulins have short half-lives, for example, rapid acting insulin analogues, where as some sulphonylureas and some forms of basal insulins (eg, insulin glargine, insulin degludec) have very long half-lives.

- Discuss with the patients and ask them to speak to their diabetes specialist about the potential effect of their medication on physical activity. If pre-exercise blood glucose level is $<5 \mathrm{mmol} / \mathrm{L}$ in individuals treated with insulin or sulphonylureas additional carbohydrate containing foods should be consumed (ie, 15 to $30 \mathrm{~g}$ in the form of sugar cubes, dextrose, sugared drinks). If the exercise duration is $>30 \mathrm{~min}$, additional carbohydrate may be needed at a rate of about 25 to 30 g per hour of exercise. ${ }^{13}$

- Exercise that is longer in duration or at intensities likely to deplete glycogen stores (including interval or intense resistance training) can increase the risk of later-onset hypoglycaemia. In such cases, consumption of 10 to $30 \mathrm{~g}$ of carbohydrate during and within $30 \mathrm{~min}$ after completing this type of exercise is recommended. ${ }^{14}$ An alternative strategy could be to reduce insulin dose by $\sim 25 \%$ at the next meal and/or reduce the basal (background) insulin by $\sim 20 \%$ for at least 6 hours. ${ }^{13}$ This should be done in conjunction with the diabetes specialist team as individuals may vary in the effect exercise has on their insulin sensitivity.

\section{CONSIDERATIONS FOR THE DOSE AND TYPES OF PHYSICAL ACTIVITY}

Generally, for participants whose blood glucose level is well controlled and within the target range noted early in the management recommendations, then normal CR intensities, durations and modes should be employed. Intensities and durations should be adjusted as noted by the guidance given. As this position statement has focussed on acute glycaemic management, further information on exercise design and prescription as emphasised earlier are well described in statements by the AACVPR, ACSM and EAPC. ${ }^{6710}$

\section{Potential exercise risks with obesity}

An important exercise consideration is the strong concomitance of obesity and diabetes and their links with bone and joint conditions. ${ }^{131132}$ The significant positive curvilinear relationship between the prevalence of diabetes and obesity, ${ }^{133}$ where over
$80 \%$ of the risk of T2DM is associated with obesity, ${ }^{134}$ means that many diabetes patients' programmes may need adapting to prevent either joint pain or potential fractures in older patients. With some participants having sensorimotor deficits from diabetes, they are at increased acute risk of falls and potentially reduced senses of acute angina during exercise. Poor skin health in the hands and feet linked with neuropathy and poorer circulation increase problems with gripping, and loss of awareness of blister formation on the feet.

\section{High intensity training}

More recently high intensity 'burst' interval training (eg, HIIT) has shown increased efficacy for aerobic fitness and muscle metabolic endurance improvements, compared with traditional moderate-vigorous continuous aerobic exercise, in CR and for people with T1DM and T2DM. ${ }^{70}{ }^{135-139}$ However, caution is advised, for those at risk of or having musculoskeletal comorbidities but more importantly in those with T1DM where hyperglycaemia and a post-exercise increased ketosis levels may occur, therefore monitoring including ketone testing is recommended.

\section{CONCLUSIONS}

With the prevalence of diabetes in the general population and its strong association with CVD, up to one-third of CR participants will need additional exercise considerations because of diabetes. Current incidence rates of diabetes would predict this programme and service challenge will continue to increase in the future. It is however important that for all with diabetes and especially those enrolled in a CR programme that every effort should be made to promote physical activity, when properly managed, as a vital component of a healthy lifestyle (cardiometabolic, circulatory, sensory-neuro-motor and psychologically). Behaviourally, the concomitance of diabetes with CVD increases the challenge for CR practitioners to impact positively behaviour change. Patients with T1DM, compared with T2DM, pose a much greater challenge to the CR practitioner in relation to both motivation and to guide and adapt exercise, including the greater risk of an exertion-related event (hypoglycaemia, hyperglycaemia and ketoacidosis). However, due to the much smaller prevalence of T1DM, most CR participants with diabetes will be T2DM, although the T2DM participants may be on insulin therapy which complicates slightly blood glucose management strategies around exercise. Important risk management considerations specific to the CR participant with diabetes include interactions between CVD and diabetes medications which can include loss of effect of some medications, augmenting chances of hypoglycaemia or hyperglycaemia. Diabetes also affects neurosensory function that can reduce symptom recognition during exercise along with the reduction of heart rate and oxygen uptake response kinetics. The time of day of exercise can modulate the reduction or the increase in risk of hypoglycaemic or hyperglycaemic events along with the type and intensity of exercise. In T2DM, afternoon sessions of HIIT are preferred over morning sessions of HIIT for glucose improvements. In contrast, for T1DM, morning sessions of any exercise format may be safer than afternoon or evening sessions since the later often result in nocturnal hypoglycaemia. A combination of muscular strength activities and aerobic endurance activities (perhaps in that given order) within any given session appears to be preferable in preventing acute and latent hypoglycaemia. For most CR participants with T2DM, they should be able to participate in the typical exercise programme unhindered. Glycaemic control in T2DM improves 
with increased physical activity levels but this is not necessarily the case for those with T1DM. There is a small proportion of T2DM participants that will need closer monitoring and more bespoke glucose managing in a similar way to the minority of CR participants who have T1DM.

\section{Author affiliations}

'Shrewsbury Centre for Active Living, University of Chester Faculty of Medicine and Life Sciences, Chester, UK

${ }^{2}$ Institute of Sport Exercise and Health, University College London, London, UK ${ }^{3}$ School of Kinesiology and Health Science, York University, Toronto, Ontario, Canada ${ }^{4} \mathrm{LMC}$ Healthcare, Diabetes and Endocrinology, Toronto, Ontario, Canada ${ }^{5}$ Aston Medical School, Aston University, Birmingham, UK ${ }^{6}$ Sport and Exercise Science, Swansea University College of Engineering, Swansea, UK

${ }^{7}$ Hotel-Dieu de Levis, Laval University Faculty of Medicine, Quebec city, Quebec, Canada

${ }^{8}$ Baker Heart and Diabetes Institute, Melbourne, Victoria, Australia

${ }^{9}$ St Vincent's Hospital Melbourne Pty Ltd, Fitzroy, Victoria, Australia

${ }^{10}$ Cardiology, Institut universitaire de cardiologie et de pneumologie de Québec,

Quebec City, Quebec, Canada

Correction notice This article has been corrected since it published Online First. Table 1 has been corrected.

Twitter John P Buckley @profjohnbuckley

Contributors We declare in keeping with the ICMJE, that: JPB provided the original conception and design of the work and all authors contributed to the drafting, acquisition of evidence and data, the critical analysis and interpretation and the critical and written structural revisions of all parts of this manuscript.

Funding The authors have not declared a specific grant for this research from any funding agency in the public, commercial or not-for-profit sectors.

Competing interests None declared.

Patient consent for publication Not required.

Provenance and peer review Not commissioned; externally peer reviewed.

ORCID iDs

John P Buckley http://orcid.org/0000-0001-6235-3395

Andre LaGerche http://orcid.org/0000-0002-3906-3784

\section{REFERENCES}

1 Harrison AS, Doherty P, Phillips A. An analysis of barriers to entry of cardiac rehabilitation in patients with diabetes: using data from the National audit of cardiac rehabilitation. Diab Vasc Dis Res 2018;15:145-9.

2 Guyatt GH, Oxman AD, Schünemann HJ, et al. Grade guidelines: a new series of articles in the Journal of clinical epidemiology. J Clin Epidemiol 2011;64:380-2.

3 Mellor DD, Langley-Evans S, Holt RIG. Update of diabetes UK evidence-based nutritional guidelines for 2018: a celebration of two leading journals working together to improve nutritional science and dietetic care for people living with diabetes. J Hum Nutr Diet 2018;31:289-91.

4 Dyson PA, Twenefour D, Breen C, et al. Diabetes UK evidence-based nutrition guidelines for the prevention and management of diabetes. Diabet Med 2018:35:541-7.

5 AACVPR. Guidelines for Cardiac Rehabilitation and Secondary Prevention Programs 5th Edition With Web Resource. In: Champaign Illinpois: human kinetics. 5th edn, 2013.

6 Lopez-Jimenez F, Kramer VC, Masters B, et al. Recommendations for managing patients with diabetes mellitus in cardiopulmonary rehabilitation: an American association of cardiovascular and pulmonary rehabilitation statement. J Cardiopulm Rehabil Prev 2012;32:101-12.

7 Kemps H, Krankel N, Dorr M, et al. Exercise training for patients with type 2 diabetes and cardiovascular disease: what to pursue and how to do it. A position paper of the European association of preventive cardiology (EAPC). Eur J Prev Cardiol 2019;2047487318820420.

8 Oldridge N, Furlong W, Feeny D, et al. Economic evaluation of cardiac rehabilitation soon after acute myocardial infarction. Am J Cardiol 1993;72:154-61.

9 Sigal RJ, Armstrong MJ, Colby P, et al. Physical activity and diabetes. Can J Diabetes 2013;37:S40-4.

10 Colberg SR, Sigal RJ, Yardley JE, et al. Physical Activity/Exercise and diabetes: a position statement of the American diabetes association. Diabetes Care 2016;39:2065-79.

11 , Sigal RJ, Armstrong MJ, et al, Diabetes Canada Clinical Practice Guidelines Expert Committee. Physical activity and diabetes. Can J Diabetes 2018;42:S54-63.
12 Riddell M, Perkins BA. Exercise and glucose metabolism in persons with diabetes mellitus: perspectives on the role for continuous glucose monitoring. I Diabetes $\mathrm{SCi}$ Technol 2009;3:914-23.

13 Riddell MC, Gallen IW, Smart CE, et al. Exercise management in type 1 diabetes: a consensus statement. Lancet Diabetes Endocrinol 2017:5:377-90.

14 Colberg SR, Albright AL, Blissmer BJ, et al. Exercise and type 2 diabetes: American College of sports medicine and the American diabetes association: joint position statement. exercise and type 2 diabetes. Med Sci Sports Exerc 2010;42:2282-303.

15 Turner G, Quigg S, Davoren P, et al. Resources to guide exercise specialists managing adults with diabetes. Sports Med Open 2019;5:20.

16 Pinsker JE, Kraus A, Gianferante D, et al. Techniques for exercise preparation and management in adults with type 1 diabetes. Can J Diabetes 2016;40:503-8.

17 Koufaki P. Exercise Testing for People with Diabetes. In: Winter EM, Jones AM, Davison RCR, et al, eds. Bases sport and exercise physiology testing guidelines. 2nd edn. Oxford: Routledge, 2007: 147-55.

18 Nagi D, Gallen I. Abcd position statement on physical activity and exercise in diabetes. Practical Diabetes International 2010;27:158-63.

19 Eckstein ML, Williams DM, O'Neil LK, et al. Physical exercise and non-insulin glucose-lowering therapies in the management of type 2 diabetes mellitus: a clinical review. Diabetic medicine : a journal of the British Diabetic Association 2019;36:349-58

20 Heden TD, Kanaley JA. Syncing exercise with meals and circadian clocks. Exerc Sport Sci Rev 2019:47:22-8.

21 Perry E, Gallen IW. Guidelines on the current best practice for the management of type 1 diabetes, sport and exercise. Pract Diab Int 2009;26:116-23.

22 Riddell MC, Burr J. Evidence-Based risk assessment and recommendations for physical activity clearance: diabetes mellitus and related comorbidities. App/ Physiol Nutr Metab 2011;36:S154-89.

23 Ryden L, Standl E, Bartnik M, et al. Guidelines on diabetes, pre-diabetes, and cardiovascular diseases: Executive summary. The task force on diabetes and cardiovascular diseases of the European Society of cardiology (ESC) and of the European association for the study of diabetes (EASD). Eur Heart J 2007;28:88-136.

24 Kotseva K, De Bacquer D, De Backer G, et al. Lifestyle and risk factor management in people at high risk of cardiovascular disease. A report from the European Society of cardiology European action on secondary and primary prevention by intervention to reduce events (EUROASPIRE) IV cross-sectional survey in 14 European regions. Eur $\mathrm{J}$ Prev Cardiol 2016:23:2007-18.

25 Cosentino F, Grant PJ, Aboyans V, et al. 2019 ESC guidelines on diabetes, prediabetes, and cardiovascular diseases developed in collaboration with the EASD. European heart journal 2019.

26 Kotseva K, Wood D, Backer GD, et al. EUROASPIRE III: a survey on the lifestyle, risk factors and use of cardioprotective drug therapies in coronary patients from 22 European countries. European Journal of Cardiovascular Prevention \& Rehabilitation 2009;16:121-37.

27 Kotseva K, Wood D, De Bacquer D, et al. EUROASPIRE IV: a European Society of cardiology survey on the lifestyle, risk factor and therapeutic management of coronary patients from 24 European countries. Eur J Prev Cardiol 2016;23:636-48.

28 NACR. National audit for cardiac rehabilitation. British Heart Foundation, York University, 2017.

29 Schofield J, Ho J, Soran H. Cardiovascular risk in type 1 diabetes mellitus. Diabetes Ther 2019;10:773-89.

30 NICE C. Lower limb peripheral arterial disease: diagnosis and management. National Insitute of health and clinical excellence 2012

31 Ansley DM, Wang B. Oxidative stress and myocardial injury in the diabetic heart. J Pathol 2013:229:232-41.

32 Patterson CC, Dahlquist GG, Gyürüs E, et al. Incidence trends for childhood type 1 diabetes in Europe during 1989-2003 and predicted new cases 2005-20: a multicentre prospective registration study. The Lancet 2009;373:2027-33.

33 You W-P, Henneberg M. Type 1 diabetes prevalence increasing globally and regionally: the role of natural selection and life expectancy at birth. BMJ Open Diab Res Care 2016:4:e00161.

34 Costacou T. The epidemiology of cardiovascular disease in adults with type 1 diabetes. Curr Diabetes Rev 2017;13:520-7.

35 Miller KM, Foster NC, Beck RW, et al. Current state of type 1 diabetes treatment in the U. S.: updated data from the T1D Exchange clinic registry. Diabetes care 2015:38:971-8

36 Rodríguez-Gutiérrez R, Montori VM. Glycemic control for patients with type 2 diabetes mellitus: our evolving faith in the face of evidence. Circulation 2016;9:504-12.

37 Mannucci E, Dicembrini I, Lauria A, et al. Is glucose control important for prevention of cardiovascular disease in diabetes? Diabetes Care 2013;36:S259-63.

38 Kourtoglou GI. Insulin therapy and exercise. Diabetes Res Clin Pract 2011;93:S73-7.

39 ACSM. ACSM's Guidelines for exercise testing and prescription. 10th ed.. Baltimore: Lippincott, Williams and Wilkins, 2017.

40 Hallal PC, Andersen LB, Bull FC, et al. Global physical activity levels: surveillance progress, pitfalls, and prospects. The Lancet 2012;380:247-57. 
41 Guthold R, Stevens GA, Riley LM, et al. Worldwide trends in insufficient physical activity from 2001 to 2016: a pooled analysis of 358 population-based surveys with 1.9 million participants. The Lancet Global Health 2018;6:e1077-86.

42 BACPR. Standards and core components of cardiovascular disease prevention and rehabilitation. 3nd Edition, 2017.

43 Cowie A, Buckley J, Doherty P, et al. Standards and core components for cardiovascular disease prevention and rehabilitation. Heart 2019;105:510-5.

44 Woodruffe S, Neubeck L, Clark RA, et al. Australian cardiovascular health and rehabilitation association (acrA) core components of cardiovascular disease secondary prevention and cardiac rehabilitation 2014. Heart, Lung and Circulation 2015;24:430-41.

45 Swift CS, Armstrong JE, Beerman K, et al. Attitudes and beliefs about exercise among persons with non-insulin-dependent diabetes. Diabetes Educ 1995;21:533-40.

46 Brazeau A-S, Rabasa-Lhoret R, Strychar I, et al. Barriers to physical activity among patients with type 1 diabetes. Diabetes Care 2008;31:2108-9.

47 Dyck RA, Kleinman NJ, Funk DR, et al. We can work (it) out together: type 1 diabetes boot cAMP for adult patients and providers improves exercise self-efficacy. Canadian Journal of Diabetes 2018;42:619-25.

48 Reddy R, Wittenberg A, Castle JR, et al. Effect of aerobic and resistance exercise on glycemic control in adults with type 1 diabetes. Can J Diabetes 2019;43:406-14.

49 Wallert J, Mitchell A, Held C, et al. Cardiac rehabilitation goal attainment after myocardial infarction with versus without diabetes: a nationwide registry study. Int $J$ Cardiol 2019;292:19-24.

50 Suzuki T, Takei R, Inoguchi T, et al. Clinical significance of barriers to blood glucose control in type 2 diabetes patients with insufficient glycemic control. Patient Prefer Adherence 2015:9:837-45.

51 Riddell MC, Pooni R, Yavelberg L, et al. Reproducibility in the cardiometabolic responses to high-intensity interval exercise in adults with type 1 diabetes. Diabetes Res Clin Pract 2019;148:137-43.

52 Turner D, Luzio S, Gray BJ, et al. Algorithm that delivers an individualized rapid-acting insulin dose after morning resistance exercise counters postexercise hyperglycaemia in people with type 1 diabetes. Diabetic Medicine 2016:33:506-10

53 Pickup JC, Ford Holloway M, Samsi K. Real-Time continuous glucose monitoring in type 1 diabetes: a qualitative framework analysis of patient narratives. Diabetes Care 2015;38:544-50

54 Gazzaruso C, Fodaro M, Coppola A. Structured therapeutic education in diabetes: is it time to re-write the chapter on the prevention of diabetic complications? Endocrine 2016;53:347-9.

55 Coppola A, Sasso L, Bagnasco A, et al. The role of patient education in the prevention and management of type 2 diabetes: an overview. Endocrine 2016;53:18-27.

56 Levesque C. Therapeutic lifestyle changes for diabetes mellitus. Nursing Clinics of North America 2017;52:679-92.

57 Pugliese G, Zanuso S, Alessi E, et al. Self glucose monitoring and physical exercise in diabetes. Diabetes Metab Res Rev 2009:25:S11-17.

58 Balducci S, Zanuso S, Fernando F, et al. Physical activity/exercise training in type 2 diabetes. The role of the Italian diabetes and exercise study. Diabetes Metab Res Rev 2009;25:S29-33.

59 Zanuso $\mathrm{S}$, Jimenez A, Pugliese $\mathrm{G}$, et al. Exercise for the management of type 2 diabetes: a review of the evidence. Acta Diabetol 2010;47:15-22.

60 Acevado EO, Ekkikakis PE. The Psychobiology of physical activity. 1st ed. Champaign, Illinois: Human Kinetics, 2006.

61 Ekkekakis P. Illuminating the black box: investigating prefrontal cortical hemodynamics during exercise with near-infrared spectroscopy. J Sport Exerc Psychol 2009;31:505-53

62 Prince SA, Blanchard CM, Grace SL, et al. Objectively-measured sedentary time and its association with markers of cardiometabolic health and fitness among cardiac rehabilitation graduates. Eur J Prev Cardio/ 2015.

63 Dempsey PC, Grace MS, Dunstan DW. Adding exercise or subtracting sitting time for glycaemic control: where do we stand? Diabetologia 2017;60:390-4.

64 Peddie MC, Bone JL, Rehrer NJ, et al. Breaking prolonged sitting reduces postprandial glycemia in healthy, normal-weight adults: a randomized crossover trial. Am J Clin Nutr 2013:98:358-66.

65 Wilmot EG, Edwardson CL, Achana FA, et al. Sedentary time in adults and the association with diabetes, cardiovascular disease and death: systematic review and meta-analysis. Diabetologia 2012;55:2895-905.

66 Edwardson CL, Gorely T, Davies MJ, et al. Association of sedentary behaviour with metabolic syndrome: a meta-analysis. PLoS One 2012;7:e34916.

67 Jones JL, Buckley JP, Furze G S. Cardiovascular prevention and rehabilitation in practice, 2nd edition. 2nd ed. London: Wiley-Blackwell, 2020April, 2020.

68 Biankin SA, Jenkins AB, Campbell LV, et al. Target-seeking behavior of plasma glucose with exercise in type 1 diabetes. Diabetes Care 2003;26:297-301.

69 Yardley JE, Kenny GP, Perkins BA, et al. Effects of performing resistance exercise before versus after aerobic exercise on glycemia in type 1 diabetes. Diabetes Care 2012;35:669-75

70 Jayawardene DC, McAuley SA, Horsburgh JC, et al. Closed-Loop insulin delivery for adults with type 1 diabetes undertaking high-intensity interval exercise versus moderate-intensity exercise: a randomized, crossover study. Diabetes Technol Ther 2017:19:340-8.

71 MacDonald MJ. Postexercise late-onset hypoglycemia in insulin-dependent diabetic patients. Diabetes Care 1987:10:584-8.

72 Lebovitz HE, Banerji MA. Ketosis-Prone diabetes (Flatbush diabetes): an emerging worldwide clinically important entity. Curr Diab Rep 2018;18:120.

73 Amiel SA. "Brittle" diabetes. BMJ 1991;303:260-1.

74 Colberg SR, Vinik Al. Exercising with peripheral or autonomic neuropathy: what health care providers and diabetic patients need to know. Phys Sportsmed 2014:42:15-23.

75 Colberg SR, Sigal RJ. Prescribing exercise for individuals with type 2 diabetes: recommendations and precautions. Phys Sportsmed 2011;39:13-26.

76 Thompson CH, Kemp GJ, Taylor DJ, et al. Effect of chronic uraemia on skeletal muscle metabolism in man. Nephrol Dial Transplant 1993;8:218-22.

77 Greenwood SA, Castle E, Lindup $\mathrm{H}$, et al. Mortality and morbidity following exercisebased renal rehabilitation in patients with chronic kidney disease: the effect of programme completion and change in exercise capacity. Nephrol Dial Transplant 2019;34:618-25

78 Tikkanen-Dolenc $\mathrm{H}$, Wadén J, Forsblom C, et al. Physical activity reduces risk of premature mortality in patients with type 1 diabetes with and without kidney disease. Diabetes Care 2017:40:1727-32.

79 Kowalchuk JM, Hughson RL. Effect of beta-adrenergic blockade on V02 kinetics during pseudorandom binary sequence exercise. Eur J Appl Physiol Occup Physiol 1990:60:365-9.

80 Keytsman C, Dendale P, Hansen D. Chronotropic Incompetence During Exercise in Type 2 Diabetes: Aetiology, Assessment Methodology, Prognostic Impact and Therapy. Sports Med 2015;45:985-95.

81 Wilson GA, Wilson LC, Lamberts RR, et al. $\beta$-Adrenergic Responsiveness in the Type 2 Diabetic Heart: Effects on Cardiac Reserve. Med Sci Sports Exerc 2017:49:907-14

82 Neves VR, Kiviniemi AM, Hautala AJ, et al. Heart rate dynamics after exercise in cardiac patients with and without type 2 diabetes. Front Physiol 2011:2:57.

83 Zinman B, Vranic M, Albisser AM, et al. Exercise and insulin absorption. N Engl J Med 1978;298:1202-3.

84 Moser O, Eckstein ML, Mueller A, et al. Pre-Exercise blood glucose levels determine the amount of orally administered carbohydrates during physical exercise in individuals with type 1 Diabetes — A randomized cross-over trial. Nutrients 2019;11:1287.

85 Campbell MD, Walker M, Trenell Ml, et al. Large pre- and postexercise rapidacting insulin reductions preserve glycemia and prevent early- but not late-onset hypoglycemia in patients with type 1 diabetes. Diabetes Care 2013;36:2217-24.

86 Zaharieva DP, McGaugh S, Pooni R, et al. Improved open-loop glucose control with basal insulin reduction 90 minutes before aerobic exercise in patients with type 1 diabetes on continuous subcutaneous insulin infusion. Diabetes Care 2019;42:824-31.

87 Rabasa-Lhoret R, Bourque J, Ducros F, et al. Guidelines for premeal insulin dose reduction for postprandial exercise of different intensities and durations in type 1 diabetic subjects treated intensively with a basal-bolus insulin regimen (ultralentelispro). Diabetes Care 2001;24:625-30.

88 Cai X, Yang W, Chen Y, et al. Efficacy of hypoglycemic treatment in type 2 diabetes stratified by age or diagnosed age: a meta-analysis. Expert Opin Pharmacother 2016:17:1591-8

89 Standl E, Erbach M, Schnell O. What should be the antihypertensive drug of choice in diabetic patients and should we avoid drugs that increase glucose levels? pro and cons. Diabetes Metab Res Rev 2012;28:60-6.

90 Standl E. Statins and beyond: concurrent strategies for prevention of cardiovascular disease in patients with type 2 diabetes. Diab Vasc Dis Res 2013;10:99-114.

91 Standl E, Schnell O, McGuire DK, et al. Integration of recent evidence into management of patients with atherosclerotic cardiovascular disease and type 2 diabetes. Lancet Diabetes Endocrinol 2017;5:391-402.

92 Poirier P. Pharmacologic and Surgical, Interventions That Prevent or Worsen, Type 2 Diabetes. In: McGuire DK, Marx N, eds. Diabetes in Cardiovascular Disease; $A$ companion to Braunwald's Heart Disease. Philadelphia: Elsevier, 2015: 57-71.

93 Kashi Z, Mahrooz A, Kianmehr A, et al. The role of metformin response in lipid metabolism in patients with recent-onset type 2 diabetes: $\mathrm{HbA} 1 \mathrm{c}$ level as a criterion for Designating patients as responders or nonresponders to metformin. PLoS One 2016;11:e0151543

94 Simonson DC, Koivisto V, Sherwin RS, et al. Adrenergic blockade alters glucose kinetics during exercise in insulin-dependent diabetics. J Clin Invest 1984:73:1648-58.

95 Sanon VP, Sanon S, Kanakia R, et al. Hypoglycemia From a Cardiologist's Perspective. Clin Cardiol 2014:37:499-504

96 Fergus IV, Connell KL, Ferdinand KC. A comparison of vasodilating and Nonvasodilating beta-blockers and their effects on cardiometabolic risk. Curr Cardiol Rep 2015; 17:38.

97 Bilinska M, Potocka J, Korzeniowska-Kubacka I, et al. 'Warm-up' phenomenon in diabetic patients with stable angina treated with diet or sulfonylureas. Coron Artery Dis 2007;18:455-62. 
98 Zheng M, LZ L, Jiang ZA, et al. [Effects of different sulfonylureas on the warm-up phenomenon in diabetes patients with coronary artery disease]. Zhonghua Yi Xue Za Zhi 2017;97:198-202.

99 Szewieczek J, Dulawa J, Strzałkowska D, et al. Normal insulin response to short-term intense exercise is abolished in type 2 diabetic patients treated with gliclazide. J Diabetes Complications 2009;23:380-6.

100 Donnan JR, Grandy CA, Chibrikov E, et al. Comparative safety of the sodium glucose co-transporter 2 (SGLT2) inhibitors: a systematic review and meta-analysis. BMJ Open 2019;9:e022577.

101 Peters AL, Buschur EO, Buse JB, et al. Euglycemic diabetic ketoacidosis: a potential complication of treatment with Sodium-Glucose cotransporter 2 inhibition. Diabetes Care 2015;38:1687-93.

102 Rosenstock J, Ferrannini E. Euglycemic diabetic ketoacidosis: a predictable, detectable, and preventable safety concern with SGLT2 inhibitors. Diabetes Care 2015:38:1638-42.

103 Zelniker TA, Wiviott SD, Raz I, et al. Sglt2 inhibitors for primary and secondary prevention of cardiovascular and renal outcomes in type 2 diabetes: a systematic review and meta-analysis of cardiovascular outcome trials. Lancet 2019;393:31-9.

104 Gomez AM, Gomez C, Aschner P, et al. Effects of performing morning versus afternoon exercise on glycemic control and hypoglycemia frequency in type 1 diabetes patients on sensor-augmented insulin pump therapy. J Diabetes Sci Technol 2015;9:619-24.

105 Gaudet-Savard T, Ferland A, Broderick TL, et al. Safety and magnitude of changes in blood glucose levels following exercise performed in the fasted and the postprandial state in men with type 2 diabetes. Eur J Cardiovasc Prev Rehabil 2007;14:831-6.

106 Savikj M, Gabriel BM, Alm PS, et al. Afternoon exercise is more efficacious than morning exercise at improving blood glucose levels in individuals with type 2 diabetes: a randomised crossover trial. Diabetologia 2019;62:233-7.

107 Colberg SR, Grieco CR. Exercise in the treatment and prevention of diabetes. Curr Sports Med Rep 2009;8:169-75.

108 Colberg SR, Zarrabi L, Bennington L, et al. Postprandial walking is better for lowering the glycemic effect of dinner than pre-dinner exercise in type 2 diabetic individuals. J Am Med Dir Assoc 2009; 10:394-7.

109 Poirier P, Mawhinney S, Grondin L, et al. Prior meal enhances the plasma glucose lowering effect of exercise in type 2 diabetes. Med Sci Sports Exerc 2001;33:1259-64.

110 Aronson R, Brown RE, Li A, et al. Optimal insulin correction factor in Post-HighIntensity exercise hyperglycemia in adults with type 1 diabetes: the fit study. Diabetes Care 2019:42:10-16.

111 McMahon SK, Ferreira LD, Ratnam N, et al. Glucose requirements to maintain euglycemia after moderate-intensity afternoon exercise in adolescents with type 1 diabetes are increased in a biphasic manner. $J$ Clin Endocrinol Metab 2007:92:963-8.

112 Wasserman $\mathrm{DH}$, Zinman B. Exercise in individuals with IDDM. Diabetes Care 1994; 17:924-37.

113 Foster NC, Beck RW, Miller KM, et al. State of type 1 diabetes management and outcomes from the T1D exchange in 2016-2018. Diabetes Technol Ther 2019:21:66-72.

114 Taylor RS, Sagar VA, Davies EJ, et al. Exercise-based rehabilitation for heart failure. Cochrane Database Syst Rev 2014:4:CD003331.

115 Anderson L, Oldridge N, Thompson DR, et al. Exercise-Based cardiac rehabilitation for coronary heart disease: cochrane systematic review and meta-analysis. J Am Coll Cardiol 2016:67:1-12.

116 Kriska AM, LaPorte RE, Patrick SL, et al. The association of physical activity and diabetic complications in individuals with insulin-dependent diabetes mellitus: the Epidemiology of Diabetes Complications Study-VII. J Clin Epidemiol 1991:44:1207-14.

117 Moser O, Eckstein ML, McCarthy 0, et al. Heart rate dynamics during cardiopulmonary exercise testing are associated with glycemic control in individuals with type 1 diabetes. PLoS One 2018;13:e0194750.
118 Thabit H, Hovorka R. Coming of age: the artificial pancreas for type 1 diabetes. Diabetologia 2016;59:1795-805.

119 Garvey K, Wolfsdorf Jl. The impact of technology on current diabetes management. Pediatr Clin North Am 2015;62:873-88.

120 Yardley JE, Iscoe KE, Sigal RJ, et al. Insulin pump therapy is associated with less post-exercise hyperglycemia than multiple daily injections: an observational study of physically active type 1 diabetes patients. Diabetes Technol Ther 2013;15:84-8.

121 Campbell MD, Walker M, Bracken RM, et al. Insulin therapy and dietary adjustments to normalize glycemia and prevent nocturnal hypoglycemia after evening exercise in type 1 diabetes: a randomized controlled trial. BMJ Open Diabetes Res Care 2015;3:e000085.

122 Moser O, Eckstein ML, Mueller A, et al. Reduction in insulin degludec dosing for multiple exercise sessions improves time spent in euglycaemia in people with type 1 diabetes: a randomized crossover trial. Diabetes Obes Metab 2019;21:349-56

123 , Greenway FL, Look AHEAD Research Group (Appendix A). Severe hypoglycemia in the look ahead trial. J Diabetes Complications 2016;30:935-43.

124 Heller SR, DeVries JH, Wysham C, et al. Lower rates of hypoglycaemia in older individuals with type 2 diabetes using insulin degludec versus insulin Glargine u100: results from switch 2. Diabetes Obes Metab 2019;21:1634-41.

125 Heise T, Bain SC, Bracken RM, et al. Similar risk of exercise-related hypoglycaemia for insulin degludec to that for insulin Glargine in patients with type 1 diabetes: a randomized cross-over trial. Diabetes Obes Metab 2016;18:196-9.

126 Ferland A, Brassard P, Poirier P. Is aspartame really safer in reducing the risk of hypoglycemia during exercise in patients with type 2 diabetes? Diabetes Care 2007;30:e59.

127 ACSM. ACSM's Guidelines for exercise testing and prescription. Baltimore: Lippincott, Williams and Wilkins, 2013.

128 BACPR. A practical approach to exercise and physical activity in the prevention and management of cardiovascular disease. London: British Association for Cardiovascular Prevention and Rehabilitation, 2014

129 Buckley JP, Furze G, Doherty P, et al. BACPR scientific statement: British standards and core components for cardiovascular disease prevention and rehabilitation. Heart 2013;99:1069-71.

130 Gallen IW, Hume C, Lumb A. Fuelling the athlete with type 1 diabetes. Diabetes Obes Metab 2011;13:130-6.

131 Walsh JS, Vilaca T, Obesity VT. Obesity, type 2 diabetes and bone in adults. Calcif Tissue Int 2017;100:528-35.

132 Chen D, Shen J, Zhao W, et al. Osteoarthritis: toward a comprehensive understanding of pathological mechanism. Bone Res 2017;5:16044.

133 Speakman JR, Heidari-Bakavoli S. Type 2 diabetes, but not obesity, prevalence is positively associated with ambient temperature. Sci Rep 2016;6:30409.

134 Diabetes-UK. Position statement, prevention of type 2 diabetes: whole-society interventions to reduce obesity, 2015. Available: wwwdiabetesorguk

135 Guiraud T, Nigam A, Gremeaux V, et al. High-Intensity interval training in cardiac rehabilitation. Sports Med 2012;42:587-605.

136 Haykowsky MJ, Timmons MP, Kruger C, et al. Meta-Analysis of aerobic interval training on exercise capacity and systolic function in patients with heart failure and reduced ejection fractions. Am J Cardiol 2013;111:1466-9.

137 Little JP, Gillen JB, Percival ME, et al. Low-Volume high-intensity interval training reduces hyperglycemia and increases muscle mitochondrial capacity in patients with type 2 diabetes. J App/ Physiol 2011;111:1554-60.

138 Moser 0, Tschakert G, Mueller A, et al. Effects of high-intensity interval exercise versus moderate continuous exercise on glucose homeostasis and hormone response in patients with type 1 diabetes mellitus using novel ultra-long-acting insulin. PLOS One 2015;10:e0136489.

139 Pandey A, Suskin N, Poirier P. The impact of burst exercise on cardiometabolic status of patients newly diagnosed with type 2 diabetes. Can J Cardiol 2017;33:1645-51. 